Journal of Engineering and Applied Sciences 15 (1): 279-282, 2020

ISSN: 1816-949X

(C) Medwell Journals, 2020

\title{
Effect of Nursing Terapeutic Communication (Spiritual Approach) Onperception, Cortisol and HSP70 Family Members with High Risk of TB Infection
}

\author{
${ }^{1}$ Chilyatiz Zahroh, ${ }^{2}$ Ah. Yusuf, ${ }^{3}$ I. Ketut Sudiana and ${ }^{4}$ Suhartono Taat Putra \\ ${ }^{1}$ Doctoral Program, Faculty of Medicine, \\ ${ }^{2}$ Faculty of Nursing, \\ ${ }^{3}$ Faculty of Medicine, Universitas Airlangga, Indonesia \\ ${ }^{4}$ Faculty of Health, Universitas Nahdlatul Ulama Surabaya, Indonesia
}

\begin{abstract}
Tuberculosis is an infectious disease. Preventive efforts are needed, so that, the members of a family who live under one roof (high risk family members) of tuberculosis patients are not easily infected by the disease. Family is involved only as a drug consumption controller. So far, there has been no effort to maintain and improve the health of high risk family members. The objective of this study was to elaborate the effect of nursing therapeutic communication on perception, cortisol and HSP70 of pulmonary tuberculosis high risk family members. A pre-experimental study was conducted using one group pre-test and post-test design. Samples obtained were 20 respondents using random sampling. The independent variable in this study was therapeutic communication (dimension of knowledge on transmission prevention and spiritual) while the dependent variable were perception (knowledge and spiritual dimensions), cortisol and HSP70. Data were collected using questionnaire and observation sheet and were tested using paired t-test. After the therapeutic communication, there was an improvement in perception $(p=0.000)$, cortisol reduction $(p=0.0005)$ and increase of HSP70 ( $p=0.004)$. There was significant difference in perception, cortisol level and HSP70 level before and after therapeutic communication. Therapeutic communication was able to improve the respondent's perception and the immunity of tuberculosis high risk family members. Recommendations to prevent TB transmission in Public Health Center of Wonokromo were; Undergoing therapeutic communication (knowledge on transmission prevention and spiritual in TB high risk family members, so that, their immunity will improve and become not easily being infected and providing training to the nurses in order to improve the elements of therapeutic communication capability.
\end{abstract}

Key words: Nursing, therapeutic communication, tuberculosis, immunity, perception, cortisol, HSP70

\section{INTRODUCTION}

Tuberculosis (TB) is an infectious disease caused by mycobacterium tuberculosis. Indonesia has implemented DOTS strategy for the management of tuberculosis, since, 1995 through strategy of TB Advocacy, Communication and Social Mobilization for Tuberculosis (AKMS). With this strategy, the government expects that the recovery rate will increase and TB will no longer become a health problem in Indonesia. However, the fact shows that the rates of TB sufferers are still high. The risk of transmission of TB depends on the number of bacteria sucked, the length of exposure, ability to attack germs and the resistance or immunity of a person. Healthy individuals are expected to be able to maintain immunity, so that, they are not easily contracted by TB. In Wonokromo Health Center, the morbidity rate comes from families of TB patients. In other words, new TB sufferers are the relatives who live in the same house with the old TB sufferers.
Prevention efforts have been carried out through the STOP TB program but the target of the program is sufferers and families in monitoring medication consumed. Therapeutic communication provided by officers is only for TB patients. So far, there has been no effort to maintain and improve health or immunity for healthy family members (family members who care for sufferers). Therapeutic communication is also needed for family members who care for TB patients, so that, TB high-risk family members are not easily infected. However, until now, the influence of therapeutic communication on changes in family member's cortisol and HSP70 high risk level of TB has not been explained. One third of the world's population is infected with Tuberculosis (TB) in which one person has TB every $4 \mathrm{sec}$ and one person dies from TB every $10 \mathrm{sec}$. There were around 9.2 million new cases of $\mathrm{TB}$ and approximately 1.7 million deaths due to TB in 2006 . There is an increase of 440,000 new cases due to Multidrug-Resistant Tuberculosis (MDR-TB) every year 
and cause at least 150,000 deaths per year. Indonesia ranks eighth out of 27 countries with high load of MDR. Tuberculosis cases in Indonesia in 2009 reached 528,063 cases and the number of deaths from tuberculosis reached 91,369 cases. Wonokromo Health Center data show an increase in TB pain every year, in 2008 the prevalence of TB patients was 25 people, in 2009 to 33 people, in 2010 as many as 38 people and in 2011 as many as 42 people. There are 4 new TB sufferers who are the family members who live at the same home with the old TB sufferers.

The TB is a disease that can spread easily. TB transmission occurs by droplet, namely through the air containing Mycobacterium TB bacteria due to coughing/sneezing from TB patients. This is a stressor for families who have TB patients as family members. Family members who frequently contacted or exposed to TB patients have a higher risk of being infected, so that, they are called high-risk family members. When a high risk family member are contracting, he/she processes the stressor inappropriately, then the perception is wrong. The wrong perception will be processed by the brain in the center of perception and emotion, the limbic system. Through the limbic system, the signal is transmitted to the hypothalamus which affects $\mathrm{CRH}$ (Corticotrophin Realizes Hormones). Stimulated CRH will affect ACTH to produce cortisol as a stress hormone. Physical stress or mental stress within a few minutes can increase ACTH secretion, so that, cortisol secretion also increases twenty-fold. It is reported that cortisol imbalance is closely related to health problems (illness). Thus, it is known that cortisol can suppress the immune system, so that, a person will be susceptible to infection. Similarly, for family members who are often exposed to TB patients who mistakenly process perceptions, cortisol levels will increase and cause high-risk families vulnerable to contracting TB infection. This will increase TB morbidity every year when it is untreated properly.

Nurses have an obligation to change the wrong perceptions of TB patient's family members. One way that nurses can do is performing therapeutic communication namely the King Interaction theory approach. The theory explains that interaction between nurses and clients is expected to be able to change perceptions and produce positive meanings, so that, positive actions emerge (Marriner-Tomey and Alligood, 2006). Similarly, the interaction between the nurses and family members who are at high risk of TB is expected to be able to change perceptions and provide positive meaning to the family members. Perception and meaning will affect the actions of high-risk family members in an effort to improve immunity. Therapeutic communication carried out by nurses contains: knowledge dimensions on how to prevent transmission of TB disease and the spiritual dimension. It is expected that therapeutic communication by nurses to high-risk family members can change the perception of high-risk family members which were initially wrong (negative) to be positive. So that, the brain will process these positive perceptions in the limbic system and continue impulses to the hypothalamus. This can inhibit CRF (Corticotrophin Releasing Factor) and ACTH to produce cortisol. Thus, the immune system of high-risk family members is not disturbed.

Aim: This study was to elaborate the effect of nursing therapeutic communication on perception, cortisol and HSP70 of pulmonary tuberculosis high risk family members.

\section{MATERIALS AND METHODS}

The research design was a pre-experimental one group pre-test post-test. The experimental and replication unit in this study were high risk TB family members in Wonokromo Community Health Center work area. There were 20 respondent as the total sampling. The inclusion criteria determined by the researchers were Muslim because the approach of communication used wasthe Islamic spiritual having family members of TB patients with BTA positive was willing to be the research respondents in healthy condition, provided by a physical examination by researchers and strengthened by a health certificate from the doctor's Wonokromo clinic, minimum education for junior high school respondents or equivalent. Meanwhile, the exclusion criteria was consuming immune suppressive drugs.

The independent variable in this study was therapeutic communication which was carried out for 3 sequential days, 30-45 min for each time of the communication. The dependent variable in this study was the perception of the high-risk family members (the knowledge dimension of preventing TB transmission) before and after the therapeutic communication. The immunity of family members who were at high risk of TB was characterized by cortisol and HSP70 levels before and after the therapeutic communication.

The data obtained were tabulated and analyzed using the statistical paired t-test with significance level $\alpha<0.05$.

\section{RESULTS AND DISCUSSION}

Table 1 shows the average score of respondent's perceptions increased in which the average score before the therapeutic communication increased by 54.3 , while after the therapeutic communication, it increased by 19.7 (delta), so that, the average score after therapeutic communication was 74 . The respondent's cortisol level decreased after the therapeutic communication in which the level before the therapeutic communication was $12.06 \mathrm{mg} \mathrm{dL}{ }^{-1}$ while after the communication it dropped to $9.37 \mathrm{mg} \mathrm{dL}^{-1}$, so, there is a decrease (delta) of 
Table 1: Results of perception scores, cortisol and HSP70 family members at high risk of pulmonary TB before and after the therapeutic communication

\begin{tabular}{|c|c|c|c|c|c|c|}
\hline \multirow[b]{2}{*}{ Variables } & \multicolumn{2}{|c|}{ Persepsi } & \multicolumn{2}{|l|}{ Kortisol } & \multicolumn{2}{|l|}{ HSP70 } \\
\hline & Pre test & Post test & Pre test & Post test & Pre test & Post test \\
\hline Mean & 54.30 & 74.000 & 12.0600 & 9.37 & 220.100 & 260.1 \\
\hline SD & 3.10 & 6.800 & 4.3000 & 3.30 & 47.700 & 61.9 \\
\hline p & 0.000 & & 0.0005 & & 0.004 & \\
\hline
\end{tabular}

Mean: Average, SD: Standard Deviation, p: Degree of significance

$2.69 \mathrm{mg} \mathrm{dL}^{-1}$ after the therapeutic communication. The HSP70 level of respondents increased after the therapeutic communication, in which the level before the therapeutic communication was $220.1 \mathrm{mg} \mathrm{dL}^{-1}$ and after communication increased to $260.1 \mathrm{mg} \mathrm{dL}^{-1}$, so, there was an increase (delta) of $40 \mathrm{mg} \mathrm{dL}^{-1}$ after therapeutic communication. There was a significant effect, before and after therapeutic communication on the perception of respondents $(p=0.000)$, cortisol levels $(p=0.0005)$ and HSP70 levels $(p=0.004)$.

Perception: Respondent's perception score has experienced a significant increase before and after the therapeutic communication. The condition of the body due to positive and negative adaptations is referred to as perceptual biology. When the body facesa stressor persistently and fails to maintain the balance, the biological perception arises in the form ofa pathological or sick state. Therapeutic communication given to respondents is expected to have positive impact on biological perceptions of the dimensions of knowledge and spirituality, so that, body balance is maintained and respondents are not sick.

It is defined that perception as the process of receiving, selecting, organizing, interpreting, testing and reacting to sensory stimuli or data. The process of selecting stimulus or stimulation is influenced by two factors, those areinternal factors and external factors. Internal factors include: psychological needs, background (education), experience, personality, general trust and self-acceptance. External factors that influence perception are intensity, contrast, movement, replication, familiarity and something new.

The demographic data of respondents were age, education and experience in caring for (long-term care for TB patients). The age factor is related to maturity and decision making, the factors of education and experience are related to one's ability to receive, process and select information from the outside while the external factors that appear are familiarity which can be interpreted as a relationship of relatives or family, besides that replication factors can also affect, considering the treatment and care of patients requires a long time (at least 6 months of treatment). Providing information repeatedly can also affect one's perception. The self-acceptance factor is included in the dimensions of spirituality, therefore, the researcher is not only used cognitive but also a spiritual approach to increase respondent's self-acceptance.

Educational data of respondent shows that respondents with the lowest education get the highest final score. This can be influenced by other factors, namely the experience of caring for patients (long-term care of patients), familiarity (relationships in the family), replication (in terms of receiving information from health workers repeatedly) and self-acceptance (respondents can accept the conditions of TB patients and sincerely caring for sufferers).

Cortisol: The respondent's cortisol levels experienced a significant decrease before and after therapeutic communication. The body's most prominent physiological response to stress is an increase in cortisol. Cortisol is an active form of blood circulation in glucocorticoids. Glucocorticoids are the main corticosteroids produced by the adrenal cortex. This secretion is controlled by the pituitary gland through Adreno Corticotrophin Hormone (ACTH). The ACTH itself is controlled through the corticotrophin relising factor. Stress will trigger an increase in blood cortisol levels. Schwertz explained that cortisol would block IL 2 receptors and suppress the production of IL 2 and IFN $\gamma$ which are Th1 cytokines. On the other hand, it is suggested that in small amounts, cortisol will stimulate the production of Th2 cytokines, IL 4 and IL 10. The normal value of cortisol at 09.00 is 170-720 nmol L ${ }^{-1}(6-26 \mu \mathrm{g} / 100 \mathrm{~mL})$. Midnight 24.00 cortisol levels are $<220 \mathrm{nmol} \mathrm{L}^{-1}(<8 \mu \mathrm{g} 100 \mathrm{~mL})$.

Physical stress or mental stress within a few minutes can increase ACTH secretion, so that, cortisol secretion also increases by twenty-fold. The stress condition experienced by a person, both physically and emotionally, will be responded by the brain in the hypothalamus. The relationship of the brain to the immune system is through the Hypothalamo Pituitary Adrenal (HPA) axis. Physical and psychological stress is processed by the hypothalamus, so that, it secretes CRH. The signal is sent to the hypophise, so, it stimulates ACTH secretion. The ACTH is captured by cells in the adrenal gland cortex to secrete cortisol. It is reported that cortisol imbalance is closely related to health problems (illness). Cortisol (glucocorticoid) plays a role in controlling the production of cytokine and this mechanism is able to stop the inflammatory process to protect organ damage in prolonged immune activity (Kunz-Ebrecht et al., 2003). Thus, it is known that an increase in cortisol can suppress the immune system, so that, a person will be susceptible to infection. All respondents indicated a decrease in cortisol levels after therapeutic communication. This shows that there is a decrease in stress experienced by respondents, so that, there is no emphasis on the immune system and respondents can maintain and improve their health even though they live in one house and care for their family members who suffered from TB. 
HSP70: Respondent's HSP70 levels increased before and after therapeutic communication. Molecular biologists explained that the heat shock protein response is a good example to describe gene expression (Morimoto, 1993). The HSP70 functions as an intracellular chaperones molecule that facilitates protein transport, prevents protein damage during folding and maintains the formation of polypeptide chains by fighting fold errors and protein denaturation (Heck et al., 2011). Asea and Maio (2007) described that HSP70 also functions as an initiator of the immune response. HSP70 is produced not only in sick people or those who are exposed to stress but it is also found in normal human serum. Research on HSP70 has always been associated with the immune system because it is more expressed in necrotic cells than apoptotic cells (Asea and Maio, 2007). The HSP70 induces an immune response, activates cells and increases the regulation and secretion of cytokines. Although, research on HSP70 focuses on the immune system, it should be noted that HSP70 was first identified as a protective chaperon. Extracellular HSP70 plays a role in protecting cells which protects the surface and enters cells.

Physical and psychological stress will stimulate the release of HSP70 with a mechanism that is not yet clearly known (Asea and Pederson, 2010). Respondents who were only 3 months old caring for TB patients had the lowest HSP70 levels. This is due to the acceptance of respondents who are less sincere in treating TB patients. Nevertheless, the respondent's final score (after therapeutic communication) has increased. Respondents (family members at high risk of TB) have a high chance of contracting TB. The HSP70 is the smallest protein in the body and is very sensitive, so what one thinks is capable of stimulating the expression of HSP70. So, HSP70 circulating in the respondent's body acts as a cell protective protein from the invasion of Mycobacterium tuberculosis. Therefore, even though there is an invasion of TB germs into the body of the respondent, it does not cause clinical manifestations because the cells in the body are able to overcome the germs attack.

\section{CONCLUSION}

Therapeutic communication enhances the immune system of family members with high risk of TB in the
Wonokromo Health Center. This characterized by a decrease in cortisol levels and an increase in HSP70 as well as an increase in perception.

\section{SUGGESTION}

Nurses need to improve therapeutic communication skills by strengthening the communication elements that have been acknowledged, so that, nursing care services can be carried out optimally. Further researchers is suggested to consider more on community cultural factors than influence behavior in health.

\section{ACKNOWLEDGEMENTS}

The author would like to thank all participants. Furthermore, author wish to thank to research centre of Universitas Airlangga and Universitas Nahdlatul Ulama Surabaya also thanks to the Ministry of Higher Education and research, Indonesia.

\section{REFERENCES}

Asea, A.A.A. and A.D. Maio, 2007. Heat Shock Proteins: Potent Mediators of Inflammation and Immunity. Springer, Dordrecht, Netherlands, ISBN: 978-1-4020-5584-3, Pages: 357.

Asea, A.A.A. and B.K. Pederson, 2010. Heat Shock Proteins and Whole Body Physiology. Springer, Dordrecht, Netherlands, ISBN: 9789048133901, Pages: 430.

Heck, T.G., C.M. Scholer and P.I.H.D. Bittencourt, 2011. HSP70 expression: Does it a novel fatigue signalling factor from immune system to the brain?. Cell Biochem. Funct., 29: 215-226.

Kunz-Ebrecht, S.R., V. Mohamed-Ali, P.J. Feldman, C. Kirschbaum and A. Steptoe, 2003. Cortisol responses to mild psychological stress are inversely associated with proinflammatory cytokines. Brain Behav. Immune., 17: 373-383.

Marriner-Tomey, A. and M.R. Alligood, 2006. Nursing Theorists and their Work. 6th Edn., Mosby/Elsevier, Missouri, USA., ISBN:9780323030106, Pages: 828.

Morimoto, R.I., 1993. Cells in stress: Transcriptional activation of heat shock genes. Science, 259: 1409-1410. 